Check for updates

Cite this: RSC Adv., 2018, 8, 26407

\title{
An efficient class of bis-NHC salts: applications in Pd-catalyzed reactions under mild reaction conditions $\dagger$
}

\author{
Chien-Cheng Chiu, Hui-Tzu Chiu, Dong-Sheng Lee (D)* and Ta-Jung Lu
}

Received 14th May 2018

Accepted 26th June 2018

This study describes an efficient class of bis-N-heterocyclic carbene (bis-NHC) salts that can be easily made from commercially available and inexpensive starting materials. The application of these salts to Pd-

DOI: $10.1039 / \mathrm{c} 8 \mathrm{ra04094j}$

rsc.li/rsc-advances

catalyzed reactions is described. The palladium $(\mathrm{Pd})$ catalyst generated in situ was highly effective under mild reaction conditions.

\section{Introduction}

Palladium-catalyzed carbon-carbon bond formation is one of the most versatile and useful tools for the synthesis of pharmaceutical compounds, advanced materials, and agricultural products. ${ }^{1}$ In the past decade, N-heterocyclic carbenes (NHCs) and their palladium complexes have demonstrated a high catalytic efficiency. ${ }^{2}$ In particular, bis-NHC-derived palladium complexes possess two strong metal-carbene bonds that are more stable than the corresponding complexes of similar monodentate carbene ligands. In addition, bis-NHC-derived palladium complexes offer many advantages, such as a superior control over the coordination sphere and tunable properties including their chirality. Recently, several bidentate bisNHC-Pd complexes have been synthesized and efficient activity has been obtained in Pd-catalyzed reactions..$^{3-5}$ However, Pdcatalyzed reactions are often carried out at a high reaction temperature in the presence of the bis-NHC-Pd catalytic system. Not only is the use of low boiling point compounds limited, but also the compounds are easily decomposed under a high temperature. It is very important to develop an efficient catalyst that allows the reaction to be carried out under mild reaction conditions.

Our group previously developed a series of bis-NHC salts that demonstrated good-to-excellent catalytic activity in Pd-catalyzed Suzuki-Miyaura coupling reactions of aryl bromides (Fig. 1). ${ }^{6}$ Generally, because it increases the electron-richness of bisNHC, the bis-NHC-Pd catalytic system has a high activity in the oxidative addition step. In 2014, Strassner et al. discussed the mechanistic cycles of a Mizoroki-Heck reaction catalyzed by bis-NHC-Pd using a density functional theory (DFT)

Department of Chemistry, National Chung-Hsing University, Taichung, 402, Taiwan. E-mail: dslee@mail.nchu.edu.tw; Fax: +886-4-22862547

$\dagger$ Electronic supplementary information (ESI) available. CCDC 1551115 and 1536791. For ESI and crystallographic data in CIF or other electronic format see DOI: $10.1039 / \mathrm{c} 8 \mathrm{ra04094j}$ calculation. ${ }^{4 e}$ They revealed that the introduction of an electrondonating groups at the para position in the aryl substitution on imidazolium salts reduced the reaction barrier of the ratedetermining step. To retain the advantage of an effective skeleton and further increase the electronic properties of bis-NHC, we used 1-(4-methoxyphenyl)benzimidazole as the main scaffold. This skeleton allows a high-potential modification through straightforward synthetic methods. In addition, the linker between the benzimidazole rings provides the flexibility to the bis-NHC-Pd complexes. Herein, we report the preparation of bis-benzimidazolium salts and the effects of different catalytic treatments in Pd-catalyzed coupling reactions.

\section{Results and discussion}

\section{Synthesis of bis-NHC salts}

The ligand syntheses started with the coupling of benzimidazole and 4-iodoanisole in the presence of copper(I) iodide (CUI) and 8-hydroxyquinalidine to form the desired product 2 with a quantitative yield. ${ }^{7}$ The bis-benzimidazolium salts 1 were obtained with an $89-96 \%$ yield through heating 2 with various dibromides in $\mathrm{N}, \mathrm{N}$-dimethylformamide (DMF) at $80{ }^{\circ} \mathrm{C}$ for $6 \mathrm{~h}$ and then $130{ }^{\circ} \mathrm{C}$ for $16 \mathrm{~h}$ in Scheme 1 . To prevent the quick formation of a precipitate, DMF was used as the solvent and a two-stage heating system was needed in the preparation of the bis-benzimidazolium salts 1 .

\section{Catalyst testing for the Suzuki-Miyaura reaction}

Biaryls formed via Suzuki-Miyaura cross-coupling are crucial scaffolds for pharmaceutical and natural products, advanced materials, and agrochemicals. The Suzuki-Miyaura crosscoupling reaction is also one of the most crucial methods for testing the efficiency of the catalyst. A general test protocol for the coupling reaction was developed by using the 4-bromoanisole 3a and phenylboronic acid $\mathbf{4 a}$ in a model study (Table 1). Initially, the reactions were performed using $\mathrm{Pd}(\mathrm{OAc})_{2}$, salts $\mathbf{1}$, 


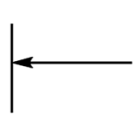

Previous work: Efficient bis-NHC for aryl bromides couplings<smiles></smiles>

This work:

Bis-NHCs bearing electronrichness group

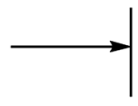

- $2 \mathrm{~B} \overline{\mathrm{r}}$

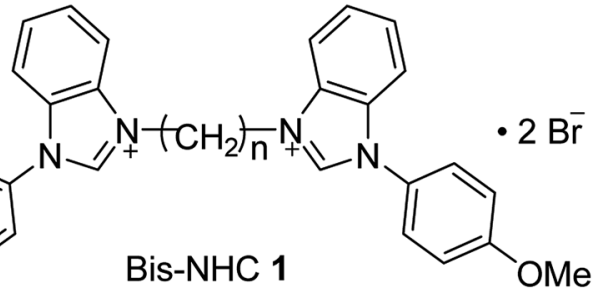

Fig. 1 Structure of bis-benzimidazolium salts 1 .

and $\mathrm{K}_{3} \mathrm{PO}_{4} \cdot \mathrm{H}_{2} \mathrm{O}$ in 1,4-dioxane at $60{ }^{\circ} \mathrm{C}$ for $24 \mathrm{~h}$ (entries 1-3). 1c was the optimal choice (entry 3 ), but a low conversion (40\%) yield was obtained. Using our previous report, ${ }^{6}$ the conversion yield was increased after modifying the reaction conditions using a two-stage temperature process. Under the two-stage temperature conditions, the $\mathrm{Pd} /$ ligand ratio was varied because low conversions may be attributed to catalytically inactive bis-ligated species generated from an excess quantity of ligands. ${ }^{8}$ The results revealed an excellent conversion (91\%) and yield $(86 \%)$ for the coupling reaction conducted at room temperature with a $1: 1 \mathrm{Pd} / \mathbf{1 c}$ ratio (entry 6). The reactions failed when acetonitrile or tetrahydrofuran (THF) were used as solvents (entries 7 and 8). The reaction could be completed in the presence of tert-butanol $(t-\mathrm{BuOH})$ (entry 9). Then, different bases were screened under a standard two-stage heating condition $\left(60^{\circ} \mathrm{C}\right.$ for $1 \mathrm{~h}$ followed by $30^{\circ} \mathrm{C}$ for $24 \mathrm{~h}$ ) (entries 10 and 11) which using $t$-BuOH as the solvent. Although both $\mathrm{K}_{2} \mathrm{CO}_{3}$ and $\mathrm{K}_{3} \mathrm{PO}_{4} \cdot \mathrm{H}_{2} \mathrm{O}$ showed excellent conversion yields (entries 9 and 10), $\mathrm{K}_{3} \mathrm{PO}_{4} \cdot \mathrm{H}_{2} \mathrm{O}$ was selected for further studies according to our previous works. ${ }^{6,9}$ Further studies<smiles>COc1ccc(-n2cnc3ccccc32)cc1</smiles>

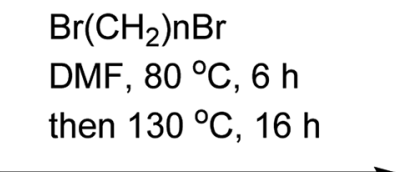<smiles></smiles>

1

$1 \mathrm{a}, \mathrm{n}=3 ; 90 \%$ yield

$1 \mathrm{~b}, \mathrm{n}=4 ; 96 \%$ yield

$1 \mathrm{c}, \mathrm{n}=5 ; 89 \%$ yield

Scheme 1 The synthesis of bis-benzimidazolium salts 1 . 
Table 1 Optimization of the reaction conditions for Suzuki-Miyaura coupling catalyzed by 1/Pd

\begin{tabular}{|c|c|c|c|c|c|c|c|}
\hline & $\mathrm{MeO}-$ & $\mathrm{Br}+$ & $4 a$ & $\begin{array}{l}\mathrm{Pd}(\mathrm{OAc})_{2} \\
\text { ligand } 1 \\
\text { eq. Base } \\
\stackrel{\text { ent }}{\longrightarrow}\end{array}$ & 5 & & \\
\hline Entry & Ligand (mol\%) & $\begin{array}{l}\mathrm{Pd}(\mathrm{OAc})_{2} \\
(\mathrm{~mol} \%)\end{array}$ & Condition $^{a}$ & Base & Solvent & Conv. ${ }^{b}$ & Yield $(\%)^{c}$ \\
\hline 1 & $1 \mathrm{a}(3.0)$ & 1.0 & A & $\mathrm{K}_{3} \mathrm{PO}_{4} \cdot \mathrm{H}_{2} \mathrm{O}$ & Dioxane & 0 & - \\
\hline 2 & $1 \mathbf{b}(3.0)$ & 1.0 & A & $\mathrm{K}_{3} \mathrm{PO}_{4} \cdot \mathrm{H}_{2} \mathrm{O}$ & Dioxane & 22 & - \\
\hline 3 & $1 \mathrm{c}(3.0)$ & 1.0 & A & $\mathrm{K}_{3} \mathrm{PO}_{4} \cdot \mathrm{H}_{2} \mathrm{O}$ & Dioxane & 40 & - \\
\hline 4 & $1 \mathrm{c}(3.0)$ & 1.0 & B & $\mathrm{K}_{3} \mathrm{PO}_{4} \cdot \mathrm{H}_{2} \mathrm{O}$ & Dioxane & 19 & - \\
\hline 5 & $1 \mathrm{c}(2.0)$ & 1.0 & B & $\mathrm{K}_{3} \mathrm{PO}_{4} \cdot \mathrm{H}_{2} \mathrm{O}$ & Dioxane & 54 & - \\
\hline 6 & $1 \mathrm{c}(1.0)$ & 1.0 & B & $\mathrm{K}_{3} \mathrm{PO}_{4} \cdot \mathrm{H}_{2} \mathrm{O}$ & Dioxane & 91 & 86 \\
\hline 7 & $1 c(1.0)$ & 1.0 & B & $\mathrm{K}_{3} \mathrm{PO}_{4} \cdot \mathrm{H}_{2} \mathrm{O}$ & $\mathrm{MeCN}$ & $<1$ & - \\
\hline 8 & $1 \mathrm{c}(1.0)$ & 1.0 & B & $\mathrm{K}_{3} \mathrm{PO}_{4} \cdot \mathrm{H}_{2} \mathrm{O}$ & THF & 4 & - \\
\hline 9 & $1 \mathrm{c}(1.0)$ & 1.0 & B & $\mathrm{K}_{3} \mathrm{PO}_{4} \cdot \mathrm{H}_{2} \mathrm{O}$ & $t$-BuOH & $>99$ & 99 \\
\hline 10 & $1 \mathrm{c}(1.0)$ & 1.0 & B & $\mathrm{K}_{2} \mathrm{CO}_{3}$ & $t$-BuOH & $>99$ & 99 \\
\hline 11 & $1 \mathrm{c}(1.0)$ & 1.0 & B & $t$-BuOK & $t$-BuOH & 16 & - \\
\hline 12 & $1 \mathrm{c}(0.5)$ & 0.5 & B & $\mathrm{K}_{3} \mathrm{PO}_{4} \cdot \mathrm{H}_{2} \mathrm{O}$ & $t$-BuOH & $>99$ & 99 \\
\hline
\end{tabular}

${ }^{a}$ Condition A: $3 \mathrm{a}(1.0 \mathrm{mmol}), \mathbf{4 a}(1.5 \mathrm{mmol}), \mathrm{Pd}(\mathrm{OAc})_{2}(1.0 \mathrm{~mol} \%)$, bis-NHC 1 (as indicated), $\mathrm{K}_{3} \mathrm{PO}_{4} \cdot \mathrm{H}_{2} \mathrm{O}(3.0 \mathrm{mmol})$ and $1,4-\mathrm{dioxane}(3.0 \mathrm{~mL})$ were stirred under $\mathrm{N}_{2}$ for $24 \mathrm{~h}$ at the indicated temperature. Condition $\mathrm{B}$ : $\mathrm{Pd}(\mathrm{OAc})_{2}(1.0 \mathrm{~mol} \%)$, bis-NHC 1 (as indicated), $\mathrm{K}_{3} \mathrm{PO} \mathrm{O}_{4} \cdot \mathrm{H}_{2} \mathrm{O}(3.0$ eq. to Pd), and 1,4-dioxane $(3.0 \mathrm{~mL})$ were stirred under $\mathrm{N}_{2}$ at $60{ }^{\circ} \mathrm{C}$ for $1 \mathrm{~h}$, followed by $3 \mathrm{a}(1.0 \mathrm{mmol}), 4 \mathrm{a}(1.5 \mathrm{mmol})$, and $\mathrm{K}_{3} \mathrm{PO}_{4} \cdot \mathrm{H}_{2} \mathrm{O}(3.0 \mathrm{mmol})$ at $30{ }^{\circ} \mathrm{C}$ for $24 \mathrm{~h}$. ${ }^{b}$ Determined by $400 \mathrm{MHz}$ NMR. ${ }^{c}$ Isolated yield.

demonstrated that the reaction could be completed even when only $0.5 \mathrm{~mol} \%$ of Pd/1c was employed (entry 12 ), which was then used as our standard reaction condition for the substrate scope exploration.

A wide range of aryl bromides were tested for the crosscoupling reaction in the presence of the $\mathrm{Pd}(\mathrm{OAc})_{2} / \mathbf{1 c}$ (0.5 mol\%) catalyst at room temperature. The results are summarized in Table 2. The coupling reaction of substrates with electron-donating or electron-withdrawing groups on the meta- or para-position of aryl bromide 3 provided excellent yields (entries 1-13), whereas the mono-ortho-substituted biaryls resulted in moderate-to-excellent yields (entries 14-16). Sterically hindered di-ortho-substituted products were also obtained in good-to-excellent yields (entries 17-20). Both the $1^{\circ}$ and $3^{\circ}$ amino groups remained intact after transformation, with 99\% and 70\% yields, respectively (entries 21 and 22). The catalytic system demonstrates high chemoselectivity at room temperature because that no Buchwald-Hartwig amination product was observed. The substrate scope could be further extended to benzyl halides with favorable yields (entries 23 and 24). The corresponding aryl bromides with naphthylboronic acid could generate various coupling products with excellent yields (entries 25-31). Furthermore, we demonstrated the high efficiency of this catalytic system. 4-Bromoanisole 3a could be coupled with phenylboronic acid $4 \mathbf{a}$ with an $87 \%$ yield with Pd loadings down to $0.005 \mathrm{~mol} \%$ (entry 2). 4'-Bromoacetophenone 3d was a possible substrate, generating the corresponding coupling product with a 99\% yield with Pd loadings down to $0.0005 \mathrm{~mol} \%$ at room temperature (entry 7). The catalytic system was compatible with a wide range of functional groups, including methoxy, nitro, ketone, aldehyde and ester. Difficult Pd-catalyzed di-ortho-substituted biaryl syntheses were also achieved in the presence of $\mathrm{Pd}(\mathrm{OAc})_{2} / \mathbf{1 c}$ with a particularly high chemoselectivity at room temperature.

\section{Catalyst testing for the Mizoroki-Heck reaction}

The Mizoroki-Heck reaction is a useful method to prepare alkylated olefins involving an $\mathrm{sp}^{2}$ carbon. In general, it is carried out in polar solvents such as $N$-methyl-2-pyrrolidone (NMP), $N, N$-dimethylacetamide (DMA) or $N, N$-dimethylformamide (DMF), in the presence of a base at a high temperature (100-150 $\left.{ }^{\circ} \mathrm{C}\right)$. A more effective catalytic system for the Mizoroki-Heck reaction under milder conditions is needed to tolerate the coupling of low-boiling olefins with aryl halides. First, we studied the use of the bis-NHC-Pd catalytic system generated in situ from $\mathrm{Pd}(\mathrm{OAc})_{2}$ and bis-NHC 1c with a 1:1 ratio for the Mizoroki-Heck reaction of 4-bromoacetophenone 3d with methyl acrylate 6a with $\mathrm{K}_{3} \mathrm{PO}_{4} \cdot \mathrm{H}_{2} \mathrm{O}$ as a base and DMF as the solvent at $60{ }^{\circ} \mathrm{C}$. However, only a $4 \%$ conversion yield was achieved. Next, we increased the conversion yield to $75 \%$ by replacing $\mathrm{Pd}(\mathrm{OAc})_{2}$ with $\mathrm{Pd}(\mathrm{dba})_{2}$ (entry 1$)$. The reaction was carried out at $60{ }^{\circ} \mathrm{C}$ in a variety of bases and solvents and the experimental results are summarized in Table 3 . Using other bases such as triethylamine $\left(\mathrm{Et}_{3} \mathrm{~N}\right), \mathrm{K}_{2} \mathrm{CO}_{3}, \mathrm{KO}^{t} \mathrm{Bu}$ and $\mathrm{KF}$ in the presence of the solvents, toluene, dioxane, acetonitrile or $t$ $\mathrm{BuOH}$ resulted in low conversion yields. When CsF in DMF was employed, the conversion yield of 7 da was improved to $99 \%$ (entry 6). 
Table 2 The coupling reaction of aryl bromides with arylboronic acids catalyzed by $1 \mathrm{c} / \mathrm{Pd}^{a}$

\begin{tabular}{|c|c|c|c|c|}
\hline Entry & $3(\mathrm{R}=)$ & 4 & Conv. ${ }^{b}$ & Yield $(\%)^{c}$ \\
\hline 1 & 4-OMe (3a) & $4 a$ & $>99$ & 5аa (99) \\
\hline $2^{d}$ & 4-OMe (3a) & $4 a$ & $>99$ & 5aa (87) \\
\hline $3^{e}$ & 4-OMe (3a) & $4 a$ & 19 & $5 \mathbf{a a}(-)$ \\
\hline 4 & $4-t-\mathrm{Bu}(3 \mathbf{b})$ & $4 a$ & $>99$ & 5ba (99) \\
\hline 9 & 4-COEt (3e) & $4 a$ & $>99$ & 5ea (99) \\
\hline $10^{d}$ & 4-COEt (3e) & $4 a$ & $>99$ & 5ea (85) \\
\hline $11^{e}$ & 4-COEt (3e) & $4 a$ & 81 & 5ea (72) \\
\hline 12 & 3 -COEt (3f) & $4 a$ & $>99$ & $5 f a(99)$ \\
\hline 13 & 4-CHO (3g) & $4 a$ & $>99$ & 5ga (99) \\
\hline 14 & $2-\mathrm{CHO}(3 \mathbf{h})$ & $4 a$ & $>99$ & 5ha (84) \\
\hline 15 & $2,4-\mathrm{DiNO}_{2}(3 \mathbf{i})$ & $4 a$ & $>99$ & $5 i a(99)$ \\
\hline 16 & $2-\mathrm{Me}(3 \mathbf{j})$ & $4 a$ & $>99$ & $5 \mathbf{j a}(70)$ \\
\hline 17 & 2,6-DiMe (3k) & $4 a$ & 98 & 5ka (85) \\
\hline 18 & 1-Bromo-2-methylnaphthalene (31) & $4 a$ & $>99$ & 5la (99) \\
\hline 19 & 1-Bromo-2-methoxynaphthalene (3m) & $4 a$ & $>99$ & $5 \mathrm{ma}(99)$ \\
\hline 20 & 1-Bromo-2,3-dimethoxynaphthalene (3n) & $4 a$ & $>99$ & 5na (99) \\
\hline 30 & $3-\operatorname{COEt}(\mathbf{3 f})$ & $4 \mathbf{b}$ & $>99$ & $\mathbf{5 f b}(96)$ \\
\hline 31 & $4-\mathrm{NH}_{2}(3 \mathbf{0})$ & $4 \mathbf{b}$ & $>99$ & 5ob (99) \\
\hline
\end{tabular}

${ }^{a}$ Reaction conditions: $\mathrm{Pd}(\mathrm{OAc})_{2}(0.5 \mathrm{~mol} \%)$, bis-NHC $1 \mathrm{c}(0.5 \mathrm{~mol} \%), \mathrm{K}_{3} \mathrm{PO}_{4} \cdot \mathrm{H}_{2} \mathrm{O}(3.0 \mathrm{~mol} \%)$ and $t$ - $\mathrm{BuOH}(3.0 \mathrm{~mL})$ were stirred under $\mathrm{N}_{2}$ at $60{ }^{\circ} \mathrm{C}$ for $1 \mathrm{~h}$, followed by $3(1.0 \mathrm{mmol}), 4(1.5 \mathrm{mmol})$, and $\mathrm{K}_{3} \mathrm{PO}_{4} \cdot \mathrm{H}_{2} \mathrm{O}(3.0 \mathrm{mmol})$ at $30{ }^{\circ} \mathrm{C}$ for $24 \mathrm{~h} .{ }^{b}$ Determined by $400 \mathrm{MHz} \mathrm{NMR} .{ }^{c}$ Isolated yield. ${ }^{d} \mathrm{Pd}(\mathrm{OAc})_{2} / \mathbf{1 c}(0.005 \mathrm{~mol} \%)$ was used. ${ }^{e} \mathrm{Pd}(\mathrm{OAc})_{2} / \mathbf{1 c}(0.0005 \mathrm{~mol} \%)$ was used. ${ }^{f} \mathrm{Pd}(\mathrm{OAc})_{2} / \mathbf{1 c}(0.00005 \mathrm{~mol} \%)$ was used.

After optimizing the reaction conditions, the substrate scope of the Mizoroki-Heck reaction was extended to a variety of substituted aryl bromides/iodides and substituted olefins (Table 4). Aryl bromides with electron-withdrawing groups, such as ketones and aldehydes, reacted with styrene to provide the corresponding products at high yields at $60^{\circ} \mathrm{C}$ (entries 2 and 3). 4-Bromobenzaldehyde $3 \mathrm{~g}$ can be coupled with 3-nitrostyrene 6c or methyl acrylate 6 a with $96 \%$ and $98 \%$ yields (entries 4 and $5)$, respectively. Even a moderate yield (61\%) was achieved by treating 4-bromobenzaldehyde $3 \mathrm{~g}$ and deactivating 2-vinylnaphthelene 6d (entry 6). Moderate yields were achieved by treating 4-bromobenzaldehyde $3 \mathrm{~g}$ or ethyl 4-bromobenzoate $3 \mathrm{~s}$ with electron-donating groups on the olefin moiety $\mathbf{3 a}$ (entries 7 and 8). The bis-NHC-Pd catalytic system exhibited less reactivity toward aryl bromides with a strong electron-donating substituent. Aryl iodides with electron-donating groups, such as methoxy group $3 \mathbf{a}^{\prime}$, reacted with methyl acrylate $\mathbf{6 a}$ or acrylonitrile of to form the desired products with a $98 \%$ or $71 \%$ yield, respectively (entries 10 and 12). Iodobenzene 3 t was coupled with olefins including methyl acrylate $\mathbf{6 a}$, acrylonitrile 6f, and styrene $\mathbf{6 b}$ with yields between $72 \%$ and $96 \%$ (entries 9 , 11 and 13). Indeed, the bis-NHC-Pd catalytic system exhibited a high catalytic reactivity under mild conditions that present the successful application to low boiling-point acrylonitrile and aryl halides.

\section{Catalyst testing for the Friedel-Crafts reaction}

The Friedel-Crafts alkylation reaction of indoles with nitroalkenes is one of the most crucial methods for preparing tryptamine and its derivatives. There are very few reports on 
Table 3 Optimizing the reaction conditions for Mizoroki-Heck reaction catalyzed by $1 \mathrm{c} / \mathrm{Pd}^{a}$

\begin{tabular}{|c|c|c|c|c|c|c|c|}
\hline & $3 d$ & $6 a$ & $\begin{array}{l}1 \\
1 \\
b\end{array}$ & $\begin{array}{l}1.0 \mathrm{~mol} \% \mathrm{Pd}(\mathrm{dba})_{2} \\
1.0 \mathrm{~mol} \% \text { bis-NHC } 1 \\
\text { base }\end{array}$ & \multicolumn{2}{|c|}{$\mathrm{Me}_{7 \mathrm{da}}^{\mathrm{O}}$} & \\
\hline Entry & Base & Solvent & Conv. $^{b}$ & Entry & Base & Solvent & Conv. ${ }^{b}$ \\
\hline 1 & $\mathrm{~K}_{3} \mathrm{PO}_{4} \cdot \mathrm{H}_{2} \mathrm{O}$ & DMF & 75 & 6 & CsF & DMF & 99 \\
\hline 2 & $\mathrm{~K}_{2} \mathrm{CO}_{3}$ & DMF & 7 & 7 & CsF & Toluene & 6 \\
\hline 3 & $\mathrm{KO}^{t} \mathrm{Bu}$ & DMF & 8 & 8 & CsF & Dioxane & 9 \\
\hline 4 & $\mathrm{KF}$ & DMF & 6 & 9 & CsF & ${ }^{t} \mathrm{BuOH}$ & 5 \\
\hline 5 & $\mathrm{Et}_{3} \mathrm{~N}$ & DMF & 18 & 10 & CsF & $\mathrm{CH}_{3} \mathrm{CN}$ & 14 \\
\hline
\end{tabular}

${ }^{a}$ Reaction condition: $3 \mathrm{~d}(1.0 \mathrm{mmol}), \mathbf{6 a}(1.5 \mathrm{mmol}), \mathrm{Pd}(\mathrm{dba})_{2}(1.0 \mathrm{~mol} \%)$, bis-NHC $1 \mathrm{c}(1.0 \mathrm{~mol} \%)$, base $(3.0 \mathrm{mmol})$ and solvent $(5.0 \mathrm{~mL})$ were stirred under $\mathrm{N}_{2}$ for $24 \mathrm{~h}$ at $60{ }^{\circ} \mathrm{C} .{ }^{b}$ Conversion was determined by $400 \mathrm{MHz}$ NMR.

Table 4 Mizoroki-Heck reactions with different substituents catalyzed by $1 \mathrm{c} / \mathrm{Pd}^{a}$

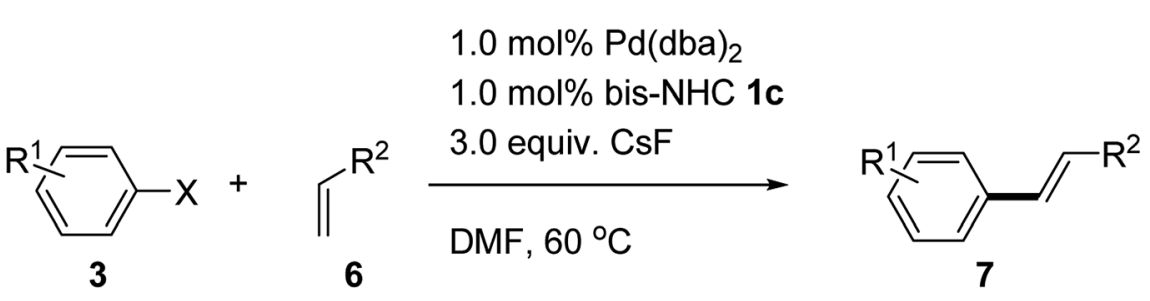

\begin{tabular}{|c|c|c|c|c|}
\hline Entry & $\mathrm{X}$ & $\mathrm{R}^{1}$ & $\mathrm{R}^{2}$ & Yield $(\%)^{b}$ \\
\hline 1 & $\mathrm{Br}$ & 4-COMe & $\mathrm{CO}_{2} \mathrm{Me}$ & $7 \mathbf{d a}(94)$ \\
\hline 2 & $\mathrm{Br}$ & 4-COEt & $\mathrm{C}_{6} \mathrm{H}_{5}$ & 7 eb (93) \\
\hline 4 & $\mathrm{Br}$ & $4-\mathrm{CHO}$ & $3-\mathrm{NO}_{2}-\mathrm{C}_{6} \mathrm{H}_{4}$ & $7 g c(96)$ \\
\hline 5 & $\mathrm{Br}$ & 4-CHO & $\mathrm{CO}_{2} \mathrm{Me}$ & 7 ga (98) \\
\hline 6 & $\mathrm{Br}$ & $4-\mathrm{CHO}$ & 2-Naphthyl & $7 g d(61)$ \\
\hline 9 & I & $\mathrm{H}$ & $\mathrm{CO}_{2} \mathrm{Me}$ & 7 ta (96) \\
\hline 10 & I & $4-\mathrm{MeO}$ & $\mathrm{CO}_{2} \mathrm{Me}$ & $7 \mathbf{a a}(98)$ \\
\hline 11 & I & $\mathrm{H}$ & $\mathrm{CN}$ & $7 t f(78)$ \\
\hline 12 & I & $4-\mathrm{MeO}$ & $\mathrm{CN}$ & 7 af $(71)$ \\
\hline 13 & I & $\mathrm{H}$ & $\mathrm{C}_{6} \mathrm{H}_{5}$ & $7 \mathbf{t b}(72)$ \\
\hline
\end{tabular}

${ }^{a}$ Reaction condition: 2 (1.0 mmol), 3 (1.5 mmol), Pd(dba $)_{2}(1.0 \mathrm{~mol} \%)$, bis-NHC 1c $(1.0 \mathrm{~mol} \%), \mathrm{CsF}(3.0 \mathrm{mmol})$ and DMF $(5.0 \mathrm{~mL})$ were stirred under $\mathrm{N}_{2}$ for $24 \mathrm{~h}$ at $60^{\circ} \mathrm{C} .{ }^{b}$ Isolated yield.

Friedel-Crafts alkylation catalyzed by bis-NHC-Pd. In fact, the Pd(II) complex can catalyze a Friedel-Crafts reaction as a Lewis acid. ${ }^{10}$ In 2008, Shi et al. have reported the synthesis of a bisNHC-Pd complex derived from binaphthyl-2,2'-diamine as well as its application for the Friedel-Crafts alkylation reaction of indole with nitrostyrene. ${ }^{11}$ The Friedel-Crafts reaction was performed in the presence of $5 \mathrm{~mol} \%$ bis-NHC-Pd complex and 5 equiv. of indole. Using low loadings of the bis-NHC-Pd complex and reducing the equivalents of indole are challenging for the Friedel-Crafts alkylation reaction catalyzed by bis-NHCPd.

In general, the acid-catalyzed conjugate addition of indoles requires careful control of the acidity to prevent polymerization. ${ }^{12}$ In 2011, Stephens et al. reported that sodium methoxide $(\mathrm{NaOMe})$ led to the polymerization of the nitrostyrene. ${ }^{13}$ In fact, the use of a base was necessary for the in situ formation of the bis-NHC-Pd complex from bis-NHC and $\mathrm{Pd}(\mathrm{OAc})_{2}$. To avoid polymerization in basic conditions, the corresponding bis- 
Table 5 Screening optimized reaction condition for Friedel-Crafts alkylation reaction ${ }^{a}$

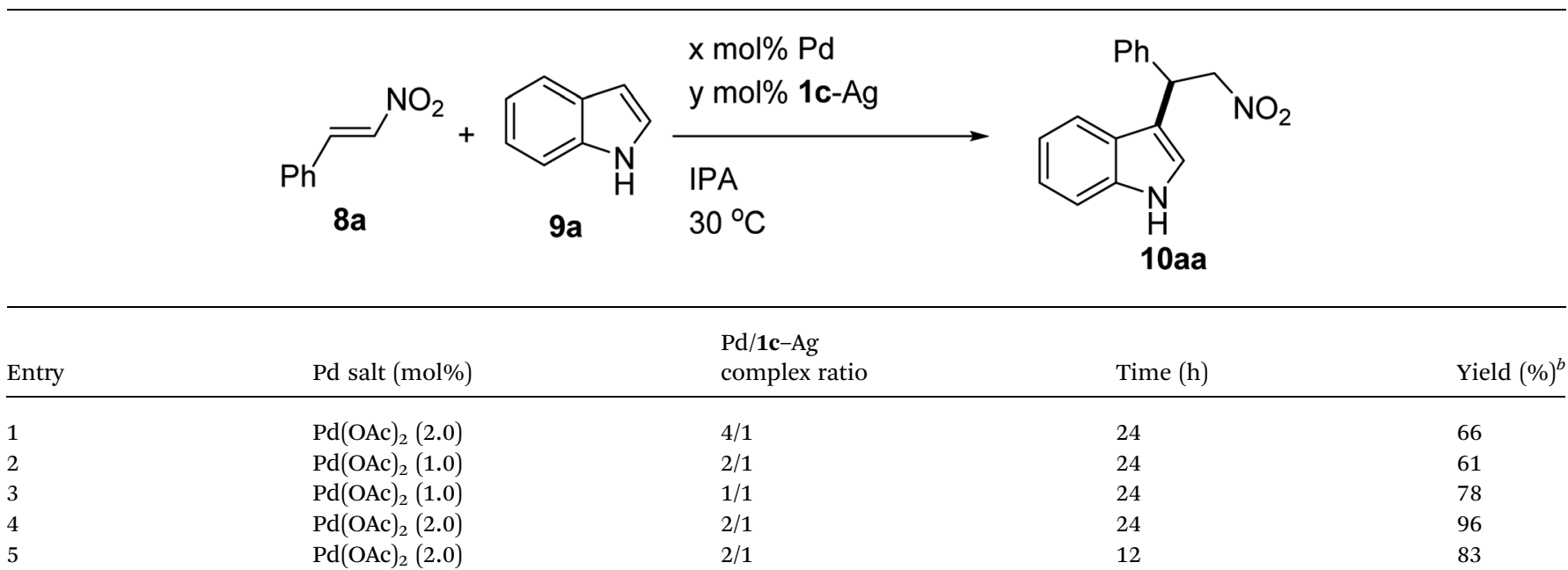

${ }^{a}$ Reaction conditions: nitrostyrene $8 \mathrm{a}(0.5 \mathrm{mmol})$, indole $\mathbf{9 a}(1.5 \mathrm{mmol})$, Pd salt (as indicated), 1c-Ag complex (as indicated), and isopropanol (3.0 $\mathrm{mL})$ are stirred for $24 \mathrm{~h}$ at $30{ }^{\circ} \mathrm{C}$ under $\mathrm{N}_{2} \cdot{ }^{b}$ Isolated yield.

NHC-Ag complex was employed as a carbene transfer agent to form the bis-NHC-Pd complex. The Friedel-Crafts alkylation reactions were tested in isopropyl alcohol (IPA) by the reaction of indole (3.0 equiv.) with nitrostyrene at $30{ }^{\circ} \mathrm{C}$ (Table 5). When varying the $\mathrm{Pd}(\mathrm{OAc})_{2} / \mathbf{1 c}-\mathrm{Ag}$ complex ratio from $4: 1$ to $1: 1$, we established that the ratio of $2: 1$ provided the optimal yield at 96\% (entry 4) (Fig. 2).
A wide range of substituted nitrostyrene compounds were coupled with indole derivatives and examined in the presence of $2.0 \mathrm{~mol} \%$ of the $\mathrm{Pd}(\mathrm{OAc})_{2} / \mathbf{1 c}-\mathrm{Ag}$ catalyst in IPA at room temperature and the results are summarized in Table 6. The results revealed that both electron-donating groups $(\mathbf{8 b}-\mathbf{8 d})$ and electron-withdrawing groups $(\mathbf{8 e}-\mathbf{8 g})$ on the nitroalkenes can form the corresponding products with favorable yields (70-

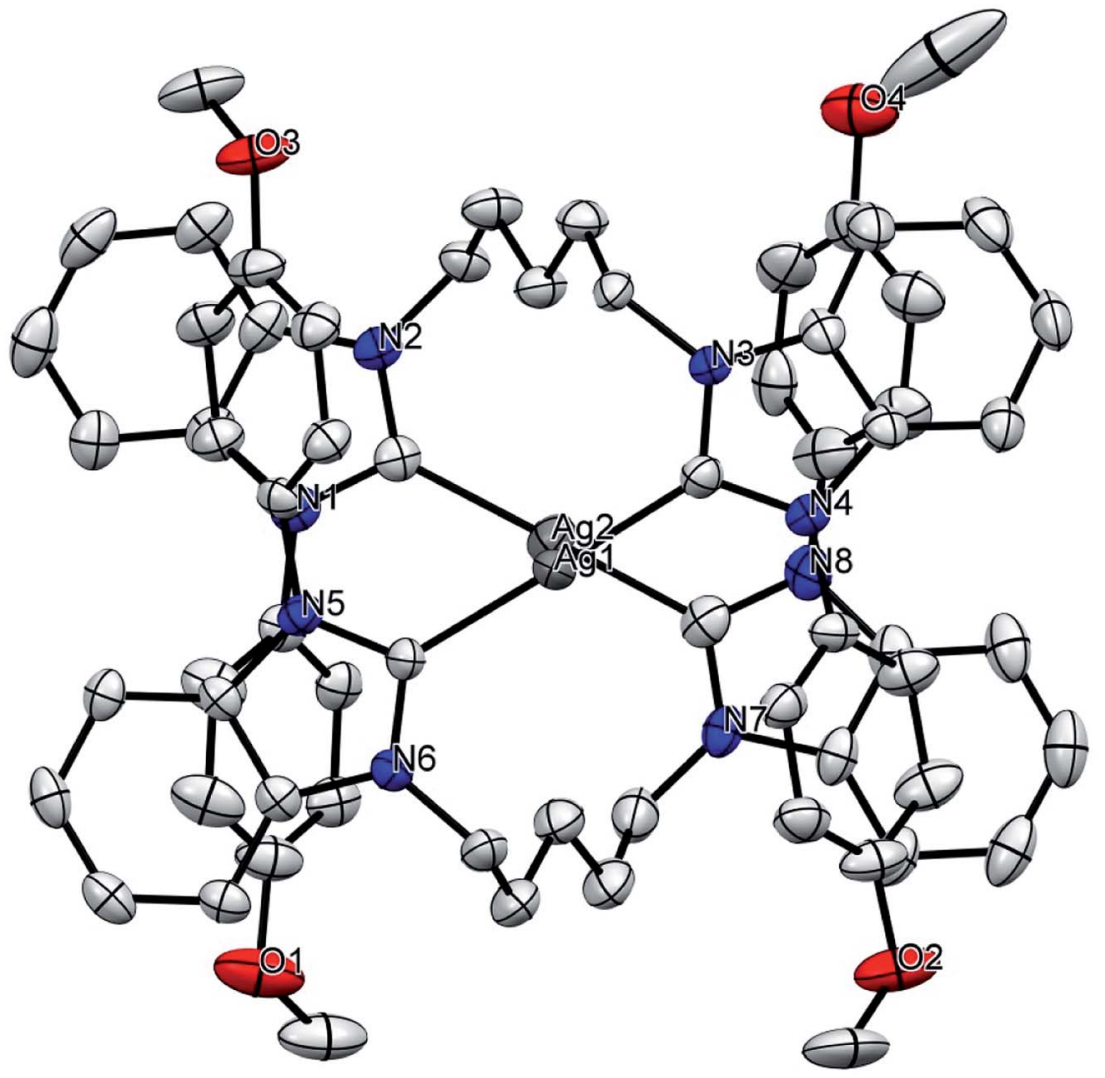

Fig. 2 Solid-state molecular structure of 1c-Ag. Hydrogen atoms, $\mathrm{PF}_{6}{ }^{-}$and solvent molecules are omitted for clarity. 
Table 6 The Friedel-Crafts alkylation reaction of alkenes and indoles catalyzed by $1 \mathrm{c}-\mathrm{Ag} / \mathrm{Pd}^{a}$
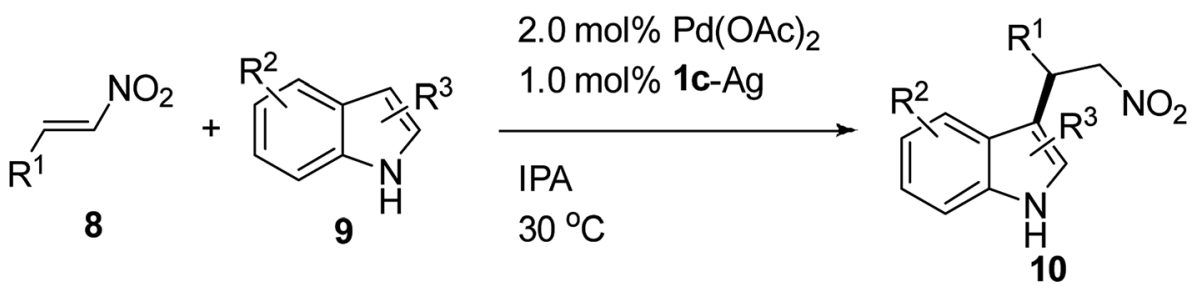

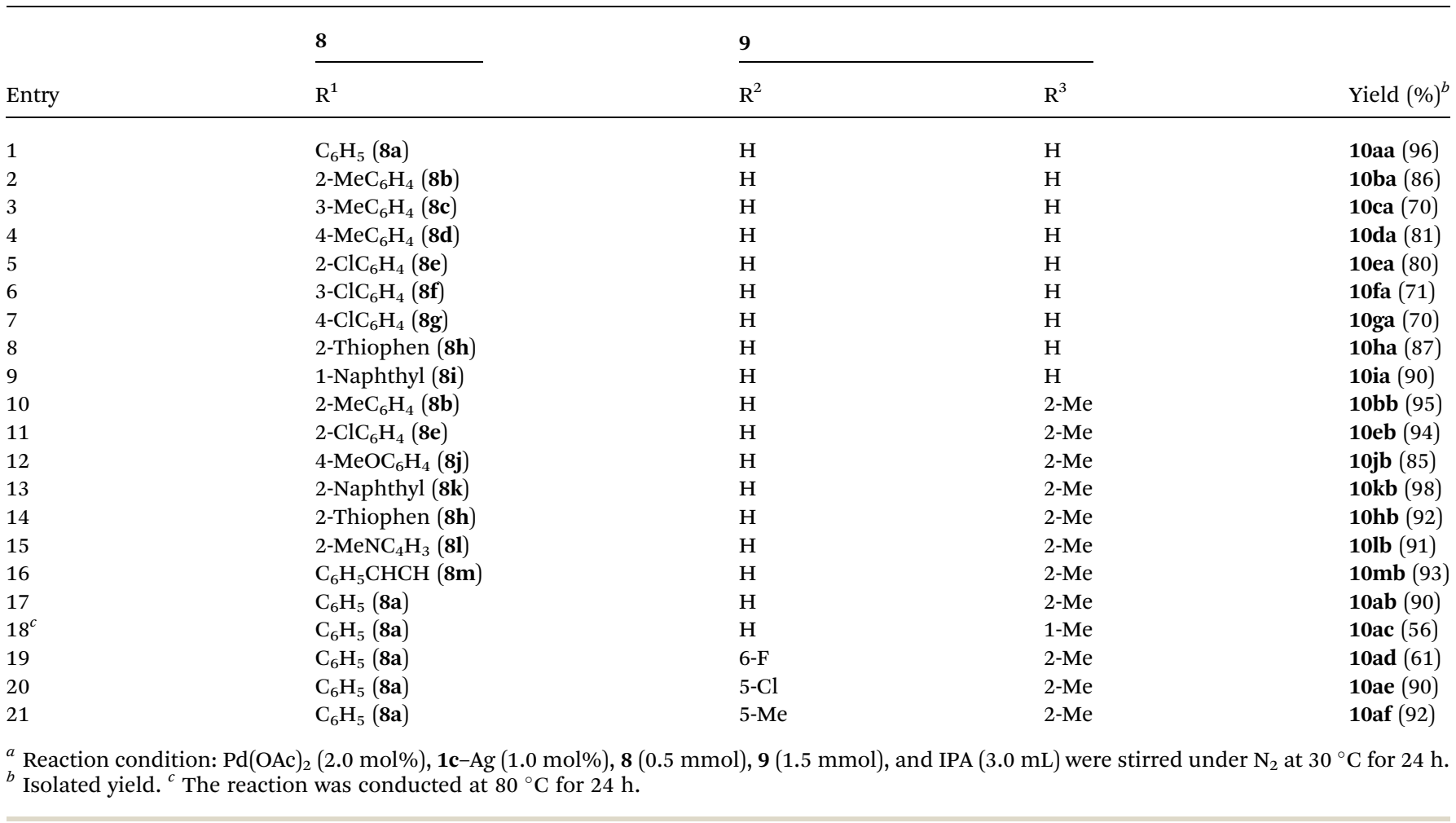

86\%) (entries 2-7). In addition, the catalytic system performed well with thiophene and naphthalene as substituents on the nitroalkenes with $87 \%$ and $90 \%$ yields, respectively (entries 8 and 9). The alkylation reaction using 2-methylindole $\mathbf{9 b}$ with nitroalkenes was also studied. Our experimental results demonstrated that when $\mathbf{9 b}$ was employed in the catalytic system, the yields were superior to those with 9a (entries 10-17). The electron-donating group on the $\mathrm{C} 2$ position of the indole increased the nucleophilicity of the indole. The yield using substrates with substituents in the ortho position were increased from $86 \%$ to $95 \%$ (entry $2 v$ s. entry 10 ) and from $80 \%$ to $94 \%$ (entry $5 v s$. entry 11), respectively. Heterocyclic systems, such as thiophene and $N$-methylpyrrole, could also be used in the catalytic system with $92 \%$ and $91 \%$ yields, respectively (entries 14 and 15). Conjugated nitroalkene $8 \mathbf{m}$ could still undergo the 1,4-addition instead of the 1,6-addition with a high regioselectivity and a $93 \%$ yield (entry 16 ). The reactivity of indole with substituents on the nitrogen decreased drastically. A $56 \%$ yield was obtained at $80^{\circ} \mathrm{C}$ for $24 \mathrm{~h}$ (entry 18). A fluorine atom on the 6-position of indole decreased its nucleophilicity and only provided a $61 \%$ yield for the Friedel-Crafts alkylation product (entry 19). Compound $\mathbf{9 e}$, where a chlorine atom is present at the 5-position and a methyl group is attached on the 2-position of the indole, produced a $90 \%$ yield (entry 20). Electron-donating groups at the 2- and 5-positions of the indole also increase its nucleophilicity, which led to a $92 \%$ of yield after transformation (entry 21) (Fig. 3).

\section{Conclusion}

In summary, the bis-NHC-Pd catalytic system exhibited a wide range of applications for the Pd-catalyzed reactions, such as the Suzuki-Miyaura reaction, the Mizoroki-Heck coupling reaction, and the Friedel-Crafts alkylation reaction. This was true whether it was generated from bis-NHC and $\mathrm{Pd}(\mathrm{OAc})_{2}$ in situ at $60{ }^{\circ} \mathrm{C}$ or using $1 \mathrm{c}-\mathrm{Ag}$ with $\mathrm{Pd}(\mathrm{OAc})_{2}$ via transmetallation at $30{ }^{\circ} \mathrm{C}$. The catalytic activity of the bis-NHC-Pd catalytic system underwent successful coupling reaction with high activities at $1.0 \mathrm{~mol} \%$ catalyst loading. The catalytic system exhibited a high selectivity between Suzuki-Miyaura cross-coupling and Buchwald-Hartwig amination reactions at room temperature. The aryl-vinyl coupling reaction of low boiling-point acrylonitrile with aryl halides was possible under mild conditions. The catalytic system could form the corresponding adducts with 


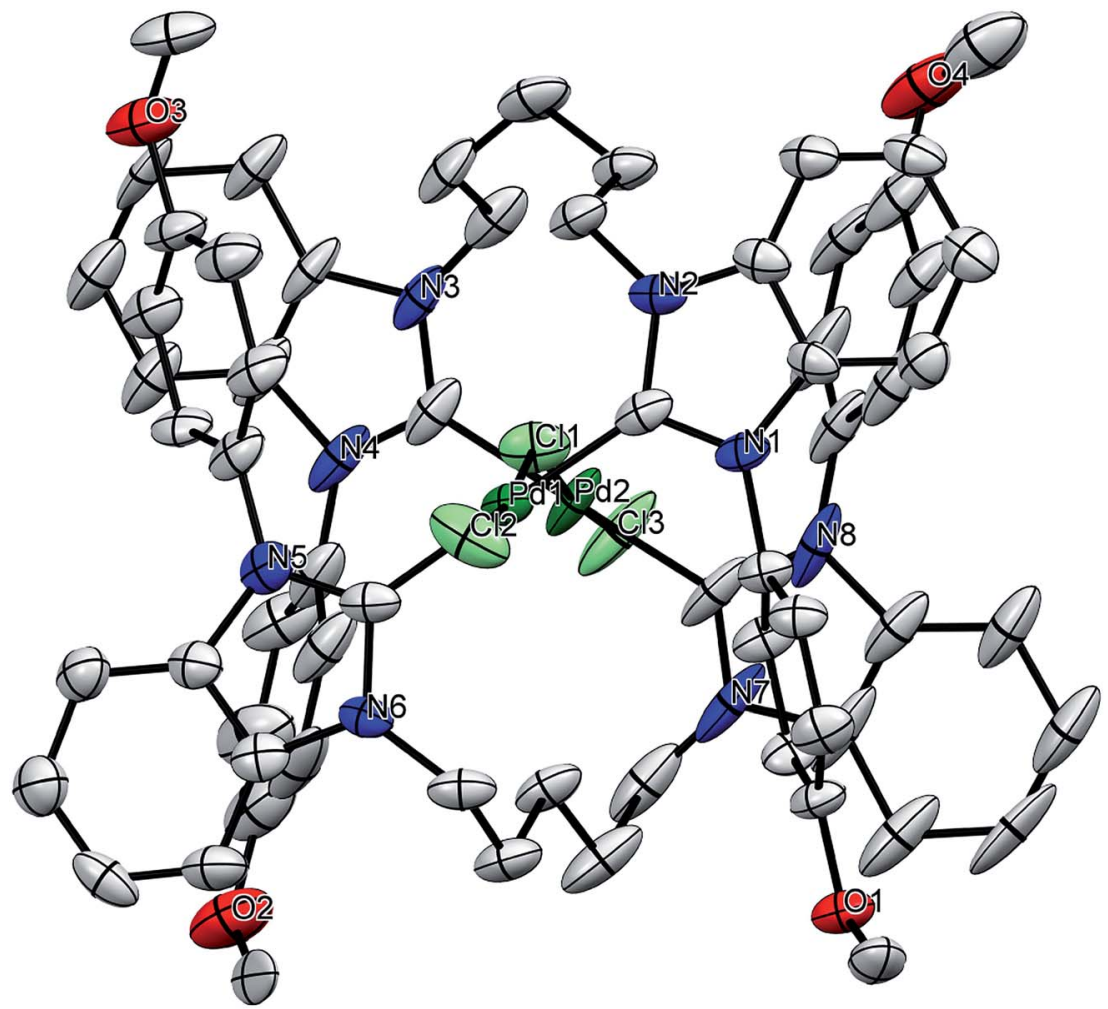

Fig. 3 Solid-state molecular structure of $1 \mathrm{c}-\mathrm{Pd}$. Hydrogen atoms, $\mathrm{PF}_{6}{ }^{-}$and solvent molecules are omitted for clarity.

favorable yields whether highly steric, electron-donating, or electron-withdrawing groups were attached on the nitroalkene. Moreover, the Friedel-Crafts adducts with indoles bearing different substituents were obtained, which overcome the issues encountered when the reaction is catalyzed by Lewis acids at ambient temperature.

\section{Experimental section}

\section{Materials and methods}

Reactions were analyzed using pre-coated silica gel 60 (F-254) plates $(0.2 \mathrm{~mm}$ layer thickness). All products were purified by column chromatography (silica gel, 0.040-0.063 $\mu \mathrm{m}$ ) using $n$ hexane/ethyl acetate as the eluent. Melting points were determined using a Mel-Temp 1001D (Barnstead/Thermo) digital melting point apparatus and are uncorrected. ${ }^{1} \mathrm{H}$ and ${ }^{13} \mathrm{C} \mathrm{NMR}$ spectra were recorded on a Varian Mercury 400 spectrometer in a solution $\mathrm{CDCl}_{3}$ with chemical shifts $(\delta)$ given in ppm relative to TMS. $J$-values are given in Hz. Chloroform $(\delta=7.26)$ was used as internal standard in the ${ }^{1} \mathrm{H}$ NMR spectra. The central peak of $\mathrm{CDCl}_{3}(\delta=77.0)$ was used as internal standard in the ${ }^{13} \mathrm{C} \mathrm{NMR}$ spectra. High resolution mass spectra were recorded using a Finnigan/Thermo Quest MAT 95XL mass spectrometer. Mass spectra were obtained using either electron impact (EI) or electrospray ionization (ESI) method. The further details for catalysts synthesis and characterization can be found in the ESI. $\dagger$

\section{Typical reaction procedure}

General procedures for Suzuki-Miyaura coupling reaction. All manipulations were carried out under nitrogen using dried solvent. The mixture of $\mathrm{Pd}(\mathrm{OAc})_{2}(0.5 \mathrm{~mol} \%), 1 \mathrm{c}(0.5 \mathrm{~mol} \%)$, $\mathrm{K}_{3} \mathrm{PO}_{4} \cdot \mathrm{H}_{2} \mathrm{O}(1.5 \mathrm{~mol} \%)$ and $t$-BuOH $(3.0 \mathrm{~mL})$ were stirred under $\mathrm{N}_{2}$ at $60{ }^{\circ} \mathrm{C}$ for $1 \mathrm{~h}$, followed by addition of aryl halide $3(1.0$ $\mathrm{mmol})$, arylboronic acid $4 \mathbf{a}$ or $\mathbf{4 b}(1.5 \mathrm{mmol})$, and $\mathrm{K}_{3} \mathrm{PO}_{4} \cdot \mathrm{H}_{2} \mathrm{O}$ $(3.0 \mathrm{mmol})$. The reaction mixture was stirred at $30{ }^{\circ} \mathrm{C}$ for $24 \mathrm{~h}$. After completion of the reaction, monitored by TLC, the reaction was quenched by water $(3.0 \mathrm{~mL})$. The aqueous layer was extracted with EtOAc $(3.0 \mathrm{~mL} \times 3)$. The combined organic layers were dried over anhydrous $\mathrm{MgSO}_{4}$ and then filtered. The solvent was evaporated under reduced pressure and the corresponding crude product of the Suzuki-Miyaura coupling reaction was purified by chromatography.

General procedures for Mizoroki-Heck coupling reaction. All manipulations were carried out under nitrogen using dried solvent. Olefin 6 (1.50 mmol), aryl halide $3(1.00 \mathrm{mmol})$, CsF (2.00 mmol), bis-NHC 1c $(1.0 \mathrm{~mol} \%)$ and $\mathrm{Pd}(\mathrm{dba})_{2}(1.0 \mathrm{~mol} \%)$ were charged to the Schlenk tube. Further dry DMF $(5.0 \mathrm{~mL})$ was added. The mixture was stirred at $60{ }^{\circ} \mathrm{C}$ for $24 \mathrm{~h}$. After completion of the reaction, monitored by TLC, the reaction was quenched by water $(5.0 \mathrm{~mL})$. The aqueous layer was extracted with EtOAc $(5.0 \mathrm{~mL} \times 3)$. The combined organic layers were dried over anhydrous $\mathrm{MgSO}_{4}$ and then filtered. The solvent was evaporated under reduced pressure and the corresponding crude product of the Mizoroki-Heck coupling reaction was purified by chromatography. 
General procedures for Friedel-Crafts alkylation reaction. All manipulations were carried out under nitrogen using HPLC grade isopropanol. Indole $9(1.50 \mathrm{mmol})$, nitroalkene $8(0.50$ $\mathrm{mmol})$, 1c-Ag (0.50 $\mathrm{mol} \%)$, and $\mathrm{Pd}(\mathrm{OAc})_{2}(1.0 \mathrm{~mol} \%)$ were charged to the Schlenk tube. Isopropanol $(3.0 \mathrm{~mL})$ was added. The mixture was stirred at $30^{\circ} \mathrm{C}$ for $24 \mathrm{~h}$. After completion of the reaction, monitored by TLC, the reaction was quenched by water $(3.0 \mathrm{~mL})$. The aqueous layer was extracted with EtOAc $(3.0 \mathrm{~mL} \times 3)$. The combined organic layers were dried over anhydrous $\mathrm{MgSO}_{4}$ and then filtered. The solvent was evaporated under reduced pressure and the corresponding crude product of the Friedel-Crafts alkylation reaction was purified by chromatography.

\section{Conflicts of interest}

There are no conflicts to declare.

\section{Acknowledgements}

We thank the Ministry of Science and Technology of the Republic of China (106WFA0550361) for financial support.

\section{References}

1 Á. Molnár, in Palladium-Catalyzed Coupling Reactions, WileyVCH, Weinheim, 1st edn, 2013.

2 (a) D. Enders, O. Niemeier and A. Henseler, Chem. Rev., 2007, 107, 5606-5655; (b) V. Nair, S. Vellalath and B. P. Babu, Chem. Soc. Rev., 2008, 37, 2691-2698.

3 For selected samples for bis-NHC-Pd catalyzed SuzukiMiyaura coupling reaction, see: (a) L. Ngodwana, S. Bose, V. Smith, W. A. L. van Otterlo and G. E. Arnott, Eur. J. Inorg. Chem., 2017, 1923-1929; (b) Ü. Yilmaz, N. Şireci, S. Deniz and H. Küçükbay, Appl. Organomet. Chem., 2010, 24, 414-420; (c) K. B. Avery, W. G. Devine, C. M. Kormos and N. E. Leadbeater, Tetrahedron Lett., 2009, 50, 28512853; (d) Q. Xu, W.-L. Duan, Z.-Y. Lei, Z.-B. Zhua and M. Shi, Tetrahedron, 2005, 61, 11225-11229; (e) G. Nan, B. Rao and M. Luo, ARKIVOC, 2011, 29-40; $(f)$ M. Shi and H.-X. Qian, Tetrahedron, 2005, 61, 4949-4955; (g) L. Seva, W.-S. Hwang and S. Sabiah, J. Mol. Catal. A: Chem., 2016, 418, 125-131; (h) Q.-X. Liu, L.-X. Zhao, X.-J. Zhao, Z.-X. Wang, A.-H. Chen and X.-G. Wang, J. Organomet. Chem., 2013, 731, 35-48; (i) S. Demir, I. Özdemir and B. Çetinkaya, Appl. Organomet. Chem., 2006, 20, 254-259; (j) M. Charbonneau, G. Addoumich, P. Oguadinma and A. R. Schmitzer, Organometallics, 2014, 33, 6544-6549.
4 For selected samples for bis-NHC-Pd catalyzed MizorokiHeck coupling reaction, see: (a) S. Demir, I. Özdemir and B. Cetinkaya, Appl. Organomet. Chem., 2009, 23, 520-523; (b) J. D. Blakemore, M. J. Chalkley, J. H. Farnaby, L. M. Guard, N. Hazari, C. D. Incarvito, E. D. Luzik, Jr. and H. W. Suh, Organometallics, 2011, 30, 1818-1829; (c) D. S. Clyne, J. Jin, E. Genest, J. C. Gallucci and T. V. RajanBabu, Org. Lett., 2000, 2, 1125-1128; (d) H. M. Lee, C. Y. Lu, C. Y. Chen, W. L. Chen, H. C. Lin, P. L. Chiu and P. Y. Cheng, Tetrahedron, 2004, 60, 58075825; (e) C. Allolio and T. Strassner, J. Org. Chem., 2014, 79, 12096-12105.

5 For selected samples for bis-NHC-Pd catalyzed reaction, see: (a) J. M. Asensio, P. Gomez-Sal, R. Andres and E. de Jesus, Dalton Trans., 2017, 46, 6785-6797; (b) Y. J. Cho, Y. N. Lim, W. Yoon, H. Yun and H. Y. Jang, Eur. J. Org. Chem., 2017, 1139-1142; (c) S. Schick, T. Pape and F. E. Hahn, Organometallics, 2014, 33, 4035-4041; (d) C. Marshall, M. F. Ward and W. T. A. Harrison, Tetrahedron Lett., 2004, 45, 5703-5706; (e) M. C. Perry, X. Cui and K. Burgess, Tetrahedron: Asymmetry, 2002, 13, 1969-1972; (f) C. Zhang and M. L. Trudell, Tetrahedron, 2000, 41, 595-598; $(g)$ A. B. Mullick, M. S. Jeletic, A. R. Powers, I. Ghiviriga, K. A. Abboud and A. S. Veige, Polyhedron, 2013, 52, 810819; (h) Z. Liu and M. Shi, Tetrahedron: Asymmetry, 2009, 20, 119-123.

6 Y.-R. Lin, C.-C. Chiu, H.-T. Chiu, D.-S. Lee and T.-J. Lu, Appl. Organomet. Chem., 2018, 32, e3896.

7 Z. H. Zhang, T. S. Li and J. J. Li, Monatsh. Chem., 2007, 138, 89-94.

8 S. Shekhar, P. Ryberg, J. F. Hartwig, J. S. Mathew, D. G. Blackmond, E. R. Strieter and S. L. Buchwald, J. Am. Chem. Soc., 2006, 128, 3584-3591.

9 M.-P. Wang, C.-C. Chiu, D.-S. Lee and T.-J. Lu, Appl. Organomet. Chem., 2018, 32, e4348.

10 K. Mikami, M. Hatano and K. Akiyama, Top. Organomet. Chem., 2005, 14, 279-321.

11 Z. Liu, T. Zhang and M. Shi, Organometallics, 2008, 27, 26682671.

12 (a) Z.-P. Zhan, R.-F. Yang and K. Lang, Tetrahedron Lett., 2005, 46, 3859-3862; (b) H. Firouzabadi, N. Iranpoor and F. Nowrouzi, Chem. Commun., 2005, 789-791; (c) M. M. Alam, R. Varala and S. R. Adapa, Tetrahedron Lett., 2003, 44, 5115-5119.

13 D. P. Gavin and J. C. Stephens, ARKIVOC, 2011, 407-421. 